\title{
An assignment based on data driven journalism: a case study
}

\section{Vanessa Simonite}

Oxford Brookes University, UK

\begin{abstract}
In a module designed to develop skills in presenting and evaluating statistics, students of mathematics and statistics were given an assignment asking them to research and write a piece of data driven journalism. Data driven journalism is a new phenomenon which has expanded rapidly due to the growth in open data, new visualisation tools and online reporting in newspapers, periodicals and blogs. The assignment provided students with a writing assignment that was individual, small-scale, research-based and embedded within their discipline.
\end{abstract}

The students were asked to formulate a research question that could be investigated using survey data available from an electronic data archive. The result of the investigation was to be written up as a piece of data driven journalism for online publication, including a data visualisation. In addition to using discipline-based skills and written communication, the assignment required students to use research skills and digital literacy.

An assignment set in the context of writing for the public extends students' writing experience beyond the domains of discipline-based professional reports and academic writing. Data driven journalism provides opportunities to develop students' writing alongside other skills for employment and can be used to design assessments for a wide range of disciplines.

Keywords: data driven journalism; data visualisation; graduate attributes; assessment.

\section{Introduction}

The development of undergraduates' writing has largely been discussed in terms of 
enabling students to participate in academic discourse within their particular discipline (Green et al., 2009) and for developing the skills and attributes needed for employment (Bridgstock, 2009; Litchfield et al., 2010), but the nature of STEM subjects and their impact on society mean that their discussion goes beyond academic and professional circles into the public domain. This case study describes an assignment in which students act as journalists, writing for an informed, though not necessarily professional, readership. Designed for students of mathematics and statistics, the disciplinary element of the assignment was achieved by making the journalism data driven, that is, based on the presentation and interpretation of data.

Data driven journalism is a rapidly growing area within both print and online media. The first conference on data driven journalism took place in August 2010 in the Netherlands (European Journalism Centre, n.d.). The Guardian newspaper's datablog (Rogers, 2012) is widely acknowledged as having been at the forefront of this new form of reporting. Visualisations providing functional, interactive and sometimes beautiful presentations of data have played an important part in the popularity and effectiveness of data driven news reports. As the open data movement has gained momentum (Berners-Lee, 2010), data visualisations play an essential role in presenting complex data to the public. A data driven journalist needs to combine skills in writing, research and analysis with digital literacy and numeracy. There is a striking overlap between these qualities and those viewed as desirable for graduate employment (Yorke and Harvey, 2005). The assignment described here addresses the questions of how to embed graduate attributes within the curriculum and how to measure the extent to which students achieve them (Green et al., 2009; Hughes and Barrie, 2010).

The following sections describe the assignment and how it can be adapted for use in other disciplines.

\section{Context}

The data driven assignment was piloted in a module entitled Communicating Statistics. The module covers topics including the presentation of statistical tables and graphs and the writing and critical evaluation of statistical reports and research papers. The module is taken by second and third year undergraduates studying mathematics or statistics, 
sometimes in degree programmes combining statistics with business or computer science. In this module, four equally weighted pieces of work were assessed: an exercise using official statistics, a written assignment, a group video project and an oral presentation, all concerned with reporting, presenting or evaluating some aspect of statistics. In the 2011/12 academic year the module was taken by 22 students and the written work consisted of the data driven journalism assignment.

The new assignment drew on material covered in lectures and computer practical classes and replaced a conventional, academic report-writing assignment. The students had learned to access data from large scale surveys held by the Economic and Social Data Service (ESDS, 2012) and had spent time discussing, creating and evaluating graphical presentations of data.

\section{The assignment}

The students were given a general topic and the names of two large datasets held by ESDS which could be accessed online. For the assignment, each student needed to identify a specific research question within the given topic and to find and use relevant data within the selected surveys to explore his or her research question. The findings were to be written up as an article of up to 450 words, suitable for publication in the form of a datablog, and including an element of data visualisation. Students were referred to the Guardian newspaper's datablog (Rogers, 2012) and encouraged to find a number of articles that they could use as exemplars.

The topic that students were asked to research was 'graduate attributes'. This concept was introduced to students by presenting the following quotation from Bowden et al. (2000):

Graduate attributes are the qualities, skills and understandings a university community agrees its students should develop during their time with the institution. These attributes include but go beyond the disciplinary expertise or technical knowledge that has traditionally formed the core of most university courses. They are qualities that also prepare graduates as agents of social good in an unknown future. 
This was followed by a list of the graduate attributes as adopted by Oxford Brookes University (OCSLD, 2011): academic literacy, research literacy, critical self-awareness and personal literacy, digital and information literacy and global citizenship.

Further discussion encouraged students to think about what, in addition to subject knowledge and understanding, they expected to be the benefits of higher education, including influences on the kind of citizens they might become. The surveys selected for students to use were the British Social Attitudes Survey 2009 (National Centre for Social Research, 2011) and the Citizenship Survey 2009-10 (Department for Communities and Local Government, 2011). The students had to use the survey data to look for evidence of the impact of higher education on respondents' attitudes, opinions, employment status or lifestyle by making comparisons either between graduates and non-graduates or between students and recent graduates. The use of statistics to investigate such topics meant that these students of mathematics and statistics were using disciplinary skills. The main output was a piece of writing, to be accompanied by a suitable graph or interactive data visualisation. To evaluate the assignment, students were asked to keep a record of the resources they accessed for the assignment and how they used them. These records were submitted to the module leader for information but were not assessed. Students also completed a brief online feedback form.

\section{Student activity during the assignment}

The students' records of how they used resources showed that six stages were involved in completing the assignment.

1. Researching graduate attributes/research question.

2. Reading examples of datablogs.

3. Using online data archive to understand and access data.

4. Data analysis, extraction and manipulation of tables.

5. Data visualisation.

6. Writing.

The students' records showed that stages 1-5 all involved using digital resources. Almost all the students had looked at university websites or electronic journals to research 
graduate attributes. The electronic data archive was used to access survey documentation and to analyse data. The students then used online visualisation tools or statistical software to represent the data graphically.

Stages 2 and 6 are concerned exclusively with written communication. Writing an article for an online newspaper was a new task for all the students, and none were familiar with data driven journalism. For the assignment, all students read examples from the Guardian datablog and, in some cases, other online publications. Journalists' writing tends to be clear and concise, setting a good example and allowing students to read several articles within the time it would take to read a single academic paper. Most students cited four or five articles.

The articles that students submitted were less formal and more fluent than their usual academic writing. Most were well written and gave a sound interpretation of the data. The data visualisations varied, as students chose different tools or different kinds of diagrams, as appropriate for their chosen data.

\section{Student evaluation and feedback}

Students were asked to record, on a scale from 1(a little) to 5 (a great deal), the extent to which the assignment required them to carry out different activities related to researching the topic, accessing data, producing visualisations and writing the blog. 'Using electronic resources to access and analyse data' was rated 4 or 5 by $77 \%$ of students. This was the activity rated as difficult by the highest percentage of students, perhaps because there were technical difficulties associated with using a particular browser. Activities related to writing received the next highest ratings: 'researching how datablogs are written' was rated as 4 or 5 by $73 \%$ of students and 'reviewing my draft article' was rated as 4 or 5 by $68 \%$ of students. Students were also asked to say what they found to be the biggest challenge in completing the assignment and their answers are summarised in Table 1. 
Table 1. Biggest challenge faced in working on the assignment: percentage of students ( $n=21$ students).

Accessing/analysing data online $\quad 29 \%$

Creating the data visualisation $19 \%$

Writing the article $19 \%$

Finding research questions/data $\quad 14 \%$

$\begin{array}{ll}\text { Time management } & 10 \%\end{array}$

Understanding open ended assignment/assessment criteria $\quad 10 \%$

Four students mentioned writing as the biggest challenge, making the following comments: 'writing up the data in an interesting way', 'writing the article was not as easy as I thought. I didn't want it to be too formal', 'sticking to the word limit' and 'thinking about how to write a suitable blog'.

\section{Benefits of the assignment}

The assignment provided a useful opportunity for mathematics and statistics students to practice written communication. Litchfield et al. (2010) argue that being able to communicate with different audiences is crucial for graduates and by writing for a public readership students gained experience of a new audience.

Beer (2002) explains that often an aversion towards writing is part of a student's attraction to studying technical, scientific or mathematical subjects. Student feedback on the assignment recognised that writing was a key activity in the assignment but did not indicate negative reactions to the task, perhaps because of the many examples available and the relatively low word limit.

The design of the assignment means that while multiple skills are developed and assessed, the assignment itself is small-scale. For the assessor, the short length of the final piece of work means that the assessment is efficient, particularly as a variety of skills are developed and tested. While the blog format limited the volume of students' output, the depth of their research and the quality of their writing and data visualisation allowed for differentiation between individuals. 


\section{Adapting to other STEM subjects and other potential developments}

For the students of mathematics and statistics who took part in the case study, the discipline-based element consisted of the analysis of data and the interpretation and visualisation of results. Many degree programmes in STEM disciplines require skills in presenting data or knowledge of statistics. Adapting the assignment for use in one of these subjects simply requires the selection of an alternative, discipline-based, topic and the provision of access to relevant data. In this way the assignment remains small-scale, with a genuine connection to the student's discipline.

Further adaptations are possible: students' work could be published online, creating exemplars for future students or forming a bridge between conventional written assignment and students' dissertations or research publications. Alternative sources of data could be used: students could make visualisations of data from a research paper or technical report, interview researchers about their work or write up one of their own laboratory or workshop projects as data driven journalism.

\section{Conclusion}

The data driven journalism assignment gave students an opportunity to develop their writing skills in a discipline-based context and has huge potential for further development. The example described here incorporated a wide range of valuable learning activities for students, but, as the articles were short, was relatively efficient for the assessor and can be adapted for assessment within a wide range of STEM disciplines.

\section{References}

Beer, D.F. (2002) 'Reflections on why engineering students don't like to write - and what we can do about it', IEEE International Professional Communication Conference. Portland, Oregon, USA September 17-20, 2002; pp. 364 - 368.

Berners-Lee, T. (2010) The year open data went world-wide. [video] Available at: http://www.ted.com/talks/tim berners lee the year open data went worldwide.ht ml (Accessed: 4 April 2012). 
Bowden, J., Hart, G., King, B., Trigwell, K. and Watts, O. (2000) Generic capabilities of ATN university graduates. Available at:

http://www.clt.uts.edu.au/ATN.grad.cap.project.index.html (Accessed: 3 April 2012).

Bridgstock, R. (2009) 'The graduate attributes we've overlooked: enhancing graduate employability through career management skills', Higher Education Research and Development, 28(1), pp. 31-44.

Department for Communities and Local Government, Ipsos MORI (2011) Citizenship Survey, 2009-2010 [computer file]. Colchester, Essex: UK Data Archive [distributor], 2011. SN: 6733. Available at: http://dx.doi.org/10.5255/UKDA-SN-6733-1 (Accessed: 27 October 2012).

Economic and Social Data Service (ESDS) (2012) Introduction to ESDS. Available at: http://www.esds.ac.uk/ (Accessed: 4 April 2012).

European Journalism Centre (n.d) What is DDJ? Available at: http://datadrivenjournalism.net/ (Accessed: 3 April 2012).

Green, W., Hammer, S. and Star, C. (2009) 'Facing up to the challenge: why is it so hard to develop graduate attributes?', Higher Education Research and Development, 28(1), pp. 17-29.

Hughes, C. and Barrie, S. (2010) 'Influences on the assessment of graduate attributes in higher education', Assessment and Evaluation in Higher Education, 35(3), pp. 325334.

Litchfield, A., Fawley, J. and Nettleton, S. (2010) 'Contextualising and integrating into the curriculum the learning and teaching of work-ready professional graduate attributes', Higher Education Research and Development, 29(5), pp. 519-534.

National Centre for Social Research (2011) British Social Attitudes Survey, 2009 [computer file]. Colchester, Essex: UK Data Archive [distributor], 2011. SN: 6695, Available at: http://dx.doi.org/10.5255/UKDA-SN-6695-1 (Accessed: 27 October 2012). 
Oxford Centre for Staff and Learning Development (2011) Brookes graduate attributes.

Available at: http://www.brookes.ac.uk/services/ocsld/sese/graduate attributes.pdf (Accessed: 4 April 2012).

Rogers, S. (ed.) (2012) Guardian datablog. Available at:

http://www.guardian.co.uk/news/datablog (Accessed: 5 April 2012).

Yorke, M. and Harvey, L. (2005) 'Graduate attributes and their development', New Directions for Institutional Research, 2005(128), pp. 41-58.

\section{Author details}

Dr Vanessa Simonite is an experienced lecturer in Statistics. She has been involved in university and HEA sponsored projects in Statistics education and applied multilevel modelling techniques to analyse undergraduate achievement. Vanessa has an additional role contributing to enhancing the student experience within the Faculty of Technology, Design and Environment at Oxford Brookes University. 